This is a manuscript version of:

Lajos Rózsa, Piotr Tryjanowski, and Zoltán Vas

Under the changing climate: how shifting geographic distributions and sexual selection shape parasite diversification

Published as chapter $4^{\text {th }}$ in:

Morand S, Krasnov B, Littlewood T (eds.) 2015. Parasite diversity and diversification: evolutionary ecology meets phylogenetics. pp 58-76. Cambridge University Press.

\title{
4.1. Introduction
}

Parasites live in an intimately close relationship with their hosts, either inserted within their anatomic structures or securely attached onto their surface. Therefore, we expect biotic effects - such as host individual, population and community characters - to influence all features of parasite communities, including richness (Poulin, 2008). In contrast, physical features of the abiotic environment, such as temperature, humidity, etc. are not usually expected to influence communities of parasites directly. The direct influence of the physical environment may be even less pronounced in terrestrial than in aquatic habitats because the terrestrial environment is less habitable for the free-living stages of parasites. Not surprisingly, major textbooks on parasite ecology rarely discuss the effects of abiotic environmental factors on terrestrial parasite assemblages (but see Bordes et al., 2010).

Currently, the ideas linking changes in abiotic factors and their influence on parasitism are associated with climate change. Global climate change is considered to be the principal abiotic environmental effect in ecological literature (Karl \& Trenberth, 2003; Rosenzweig et al., 2008). Whether partially anthropogenic or not, climate change produces shifts in the distributions and 
abundances of populations and species (Parmesan \& Yohe, 2003) and poses a major extinction risk to many species (Thomas et al., 2004).

In this chapter we consider the relationship between host range shifts and parasite diversification. Earlier authors have repeatedly emphasized two major points: (1) the ongoing loss of non-parasite diversity decreases parasite diversity (Lafferty, 2012); and (2) periods of expansions of hosts' geographical ranges promote host-switches (Hoberg \& Brooks, 2008). Below we outline a scenario that adds three further aspects:

1. We separately discuss the characteristic processes of the leading edge versus the rear edge of the moving margins of the hosts' range.

2. We show that both relatively high or relatively low parasite richness of an invasive host population may facilitate invasion success under different circumstances.

3. We analyse the role of sexual selection in parasite speciation in relation to their geographic position.

4.2 Changing parasite communities and shifts in hosts' geographic ranges

\subsubsection{Shifting host distributions}

Host geographic ranges relentlessly change due to natural processes; however, human-induced effects, such as environmental pollution, deforestation, agriculture, desertification, overfishing of marine and overgrazing of terrestrial ecosystems, and climate change in particular, may force them to make unusually quick shifts. A global metaanalysis indicates that free-living species shift their ranges poleward at an average speed of $6.1 \mathrm{~km}$ per decade, likely due to climate warming (Parmesan \& Yohe, 2003). Therefore, understanding the interactions between host range shifts and parasite speciation and extinction events is crucial for making predictions about future parasite and pathogen assemblages of humans, domestic animals and wildlife. Imagine a virtual host population whose geographic distribution is gradually shifting in one direction, say, withdrawing from the south and extending into the north. Following a simple idea introduced by 
Hampe and Petit (2005) we discriminate between leading edge effects on the north and rear edge effects on the south.

\subsubsection{Leading edge populations}

Environmental changes may render large and formerly uninhabitable areas open to colonization for many species, e.g. climate change may facilitate poleward range shifts, particularly in cold and temperate regions. In a typical model of colonization that became almost a central paradigm in phylogeography, the process involves rare and accidental long-distance dispersal events followed by exponential growth of isolated host populations. The population genetic bottlenecks explain the low level of genetic diversity observed both within and among these leading edge populations (Hewitt, 2000). Moreover, founding events are also likely to decimate the richness of their parasite and pathogen assemblages. Not only species richness, but also genetic diversity of the few co-colonizing parasite species is reduced within the founder populations. According to the Enemy Release Hypothesis (ERH) (Keane \& Crawley, 2002; Torchin et al., 2003), introduced invader species harbour significantly poorer pathogen faunas than their source populations; thus they may often outcompete locally endemic rival species that carry rich parasite faunas causing higher metabolic burdens.

Consequently, at the leading edge of the host range, the genetically homogeneous populations that harbour species-poor parasite and pathogen assemblages may exhibit exponential population booms. Predictably, these leading edge populations will be susceptible to hostswitching parasites and pathogens carried by the host species they encounter in their expanded range (Hoberg \& Brooks, 2008). Subsequently, as the metabolic advantages of their relatively parasite-free state is gradually eroded by switches from the local parasite and pathogen fauna, they fail to grow further in numbers or may even collapse and disappear.

Host-switching is a sudden change in the host-specificity of a particular parasite lineage, often accomplished by only a very few founder individuals that colonize a host species that has not been regularly utilized formerly. Obviously, most such switches result in immediate extinction of the switching parasite lineage. In a few rare cases, however, the invaders succeed in establishing a viable population on the new host species. Assuming that parasite transmission is largely restricted within the boundaries of the host species, such as in the case of sexually or 
socially transmitted pathogens, a reproductively isolated host race emerges that may subsequently give rise to a separate parasite species. The parasites' source population is not at all affected by this process but keeps on parasitizing its original host species. In the case of colonizing host populations, the success of host-switches is enhanced by the growing size and low genetic diversity of the host population, and the low species richness and low genetic diversity of their pathogen community.

In this age the human species (Homo sapiens) exhibits an unprecedented geographic expansion. Humankind continuously increases its range and invades habitats and ecosystems more extensively and intensively than ever before. Thus, humans establish contact with more and more species; consequently, emerging infectious diseases of zoonotic origin are expected to occur more frequently at the periphery of the advancing front (Reperant, 2010; Murray et al., 2012).

In human historical geography, 'McNeill's law' (McNeill, 1976) postulates an alternative scenario. It assumes that the successful expansion of certain nations to conquer rivals has been facilitated by their superior pathogen richness (McNeill, 1976). This hypothesis presumes that large and spatially central populations of humankind share a long coevolutionary history with rich pathogen assemblages, unlike the long-isolated, small and peripheral populations that harbour species-poor parasite assemblages. Therefore, invasions from the centre to the marginal populations may be facilitated by the rich co-invasive pathogen assemblages. Members of peripheral populations are less able to develop appropriate immune reactions. They are not only more susceptible to infections, but also the pathogens are selected to increase virulence once circulating in immunologically naive populations (Ewald, 1994). Indeed, European nations colonizing other continents were able to populate regions of Siberia, the Americas, Australia and New Zealand - exactly those areas whose aboriginal populations were founded by relatively small groups of founder individuals and later developed in long isolation from the main, central human populations (Diamond, 1997).

Although McNeill's law was originally postulated to describe the pathogen-mediated relationship among human (i.e. conspecific) populations, closely related host species may also engage in similar relationships. One can find several examples of pathogen mediated negative interactions (also as 'parasite-mediated competition' or 'apparent competition') among different host species in the literature (Hudson \& Greenman, 1998; Tompkins et al., 2002; Ricklefs, 2010). Essentially, 
the co-invasive pathogen is less virulent and more transmissive in the invasive species than in the host they mutually displace.

There appears to be a contradiction between this generalized form of McNeill's law and the $\mathrm{ERH}$. Are the invasions of certain populations or species facilitated by the parasites they distribute to their competitors or, alternatively, by low species richness and genetic diversity of parasites on the invaders? Here, we propose that both scenarios may occur depending on the modes of invasion.

Pioneer-based invasions are initiated by rare, long-distance migrants that establish distant and isolated populations far away from the source population. Host genetic diversity, parasite species richness and genetic diversity are all reduced in their founder populations even long after a subsequent increase of population size. Most introduced exotic species appear to fit this scenario, and we predict they will also fit the ERH. Other invasions, however, are characterized by a sudden mass inflow of migrants, thus no founder effect occurs. For example, soon after the technological development enabled Europeans to cross the oceans, a mass of European people colonized distant, formerly isolated continents. As 'McNeill's rule' predicts, they displaced native people partly because they carried a species-rich and genetically diverse pathogen assemblage. Similarly, the current mass transportation of materials - such as ballast water carried by ships - has enabled many species to make mass inflows into formerly isolated, distant areas. Moreover, the mass introduction of domestic, feral and game animals may also fit this pattern. Such non-native mass invaders are likely to carry the (nearly) full genetic diversity of source host populations along with their species-rich and also genetically diverse parasite faunas. In such cases, we expect successful invaders may obtain a competitive advantage within the context of parasite-mediated competition.

Apparently, sudden mass invasions are rare and mostly human-induced events. Therefore, we consider pioneer-based invasions followed by an exponential growth of isolated, pathogen-poor populations to be the main mode of colonization at the leading edges of host area expansions. 


\subsubsection{Rear edge populations}

At the rear edge of a gradually shifting range, host populations face an increasingly inhospitable environment. Some of the rear edge populations become completely extirpated, along with the entire parasite fauna they harbour. Others - whenever a heterogeneous topography allows become relict populations inhabiting small and isolated habitat patches that may provide refugia for long-term survival (Hewitt, 2000; Petit et al., 2003). These rear-edge relict populations are restricted to habitat islands embedded within a matrix of already unsuitable landscapes. Being small and isolated through long periods, their within-population genetic diversity decreases while they also exhibit high levels of genetic differentiation among each other. Selection for local adaptation rather than for vagility and variability results in the development of distinct ecotypes (Dynesius \& Jansson, 2000). Even though some relict populations are surprisingly persistent, they gradually shrink in size and eventually disappear long after being isolated from the main host distribution. Given the long evolutionary period of host population size decline, some parasite species may have a chance to gradually abandon the shrinking host population by the process of 'host-shifting'.

Although the terms 'host-switch' and 'host-shift' are routinely used as synonyms in the literature, we refer to them as two different processes. Hereafter, the term 'host-shift' is used to signify a parasite species' gradual abandonment of a shrinking host population (Figure 4.1). Apparently, most parasite species parasitize more than one host species (Poulin, 2008). One (or a very few) host species act as primary hosts supplying the majority of the parasites' reproductive success, thus the parasite must be well adapted to it. Most parasites also utilize secondary host species. They are much less adapted to these secondary hosts and their reproductive success is depressed on them. A permanent flow of parasite spores, eggs or larvae prevents isolation between the parasite populations living on different host species and, therefore, prevents improvement of parasite adaptation to the secondary hosts. The position of primary versus secondary host species - their relative role from a parasite's perspective - may change through time. Provided the primary host gradually becomes scarcer and less accessible for parasite transmission, a gradually increasing proportion of the parasite population will be forced to utilize the secondary hosts. Selective pressures to increase adaptation to the secondary host will reduce adaptation to the primary hosts due to a trade-off between the two alternative adaptation repertoires. Finally, the former secondary host becomes a primary one, while the former primary host may either become a secondary host or even become totally abandoned. This process, 
which we call host-shifting here, is not a sudden, stochastic and highly unpredictable event, but rather a slow and gradual evolutionary process.
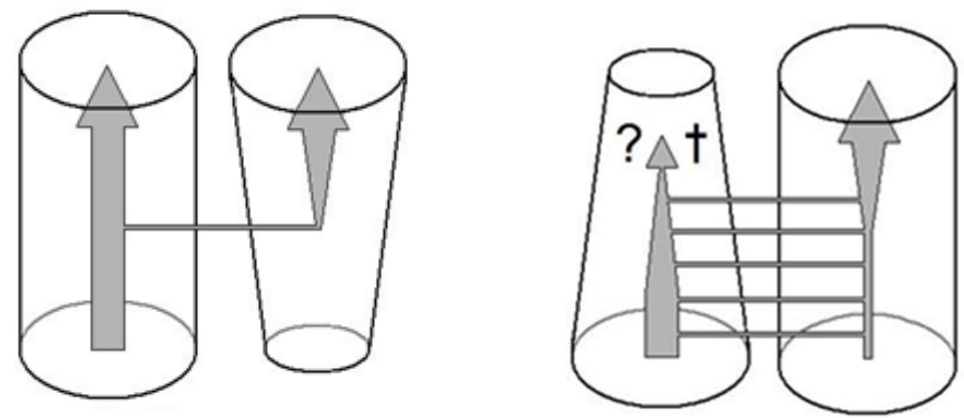

Figure 4.1 Host-switch (left) is a sudden, random colonization (vertical line) of a new, formerly unused host species by a few parasite individuals. It does not affect the further fate of the conspecific parasites on the donor host species, may accidentally cross large taxonomic gaps between the donor and the recipient hosts, and it may lead to parasite speciation. Host-shift (right) is a gradual change of the relative role of a particular host species as primary versus secondary host in the case of a potentially multi-host parasite. Horizontal lines represent frequent cross-infections between the two host species. The former primary host either becomes a secondary host or becomes totally abandoned by the parasite. This process is a gradual change that does not increase parasite diversity. Host-switch is more likely to occur in a growing host population, and host-shift is more likely to occur in a shrinking host population. 


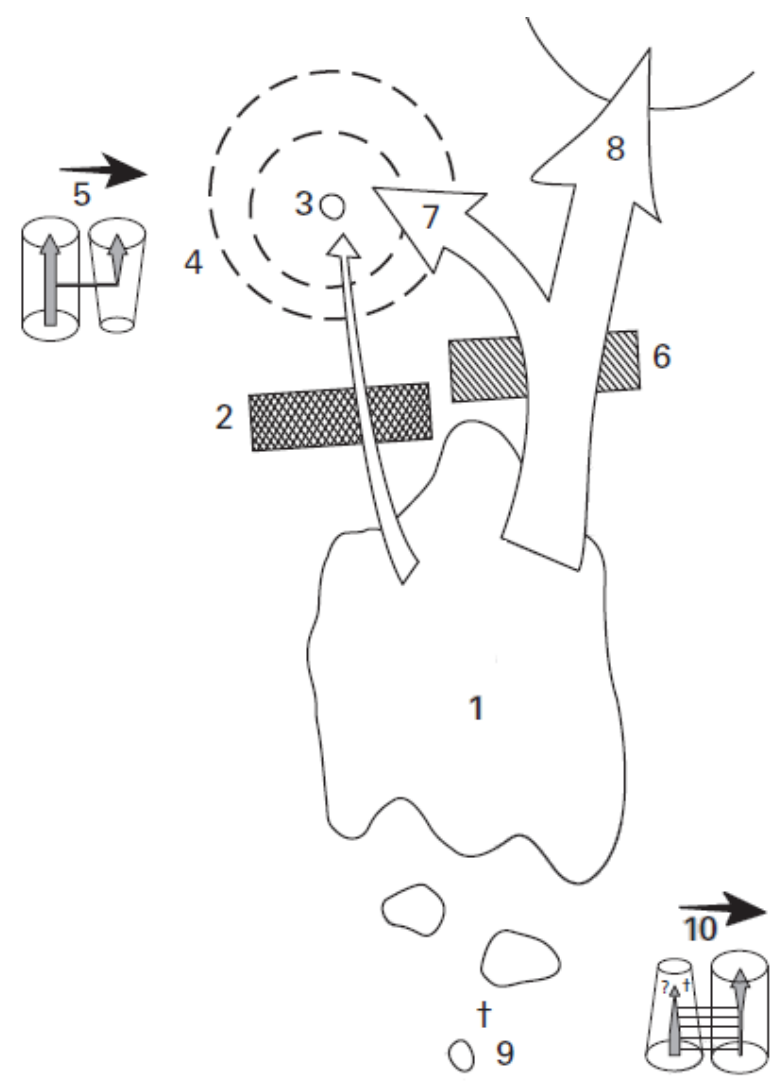

Figure 4.2 A schematic representation of the characteristic processes shaping the pathogen community harboured by a host taxon with moving (here: south!north) geographic area. At the leading edge of the host's main geographic area (1), an environmental barrier (2) blocks northward invasion, so that only a very few pioneer individuals may cross it to establish a small and isolated population (3) that has a reduced genetic diversity and a species-poor and genetically homogenous parasite fauna. Subsequently, this host population may enjoy a competitive advantage against members of the local fauna (not illustrated here) because of their reduced parasite burden. Consequently, the invasive founder population may increase its size (4), increasing the chance of host-switches (5). Another environmental barrier (6) may suddenly disappear to enable a mass inflow of invaders from the source population. According to McNeill's law, such genetically diverse and pathogen-rich mass invasions may either outcompete a conspecific population (7) or populations of other species (8) harbouring a species-poor parasite assemblage. Meanwhile, at the rear edge of the moving area, certain host populations get isolated from the main area and gradually shrink in size and genetic diversity. Members of their parasite faunae may either go extinct (9) or shift their host range to abandon the shrinking host population and utilize others (10). 
4.3. Sex, speciation and virulence at the speciation centre: a case study with lice and pocket gophers

\subsubsection{Background}

The complex view that arises from the mosaic of the abovementioned processes (Figure 4.2) still lacks an influential factor affecting parasite speciation, i.e. the presence or absence of closely related parasite species, subspecies and populations.

We presume that the availability of closely related host lineages is an important factor in parasite speciation because host-shifts and host-switches are more likely to occur between them than is expected by chance (Krasnov et al., 2004).

The geographic distribution of several higher taxa of free-living animals can be characterized by a centre of speciation. These speciation hotspots are geographic areas where the formation of new species is particularly intensive and, consequently, a high number of closely related taxa occur sympatrically. Below, we investigate whether host and parasite populations' spatial position at the speciation centre versus at the speciespoor peripheries influences levels of sexual selection and speciation in parasites. Since this question is not addressed in the currently available literature, we take the liberty to delineate a formerly unpublished comparative study below. Only preliminary versions of this study have previously been briefly described in Hungarian (Rózsa, 2005).

Sexual reproduction in free-living organisms is thought to have originated and maintained as an adaptive response to parasitism (Hamilton et al., 1990). However, parasites themselves tend to reproduce sexually too. Sexual selection occurs when mating success is influenced by different genotypes. While sexual selection is accepted as a major force of evolution (including speciation) of free-living species (Anderson, 1994), and pathogens' influence on host sexual selection has been studied intensively in recent decades, effects of sexual selection in parasites is still poorly understood.

We compare sexual size dimorphism, sex-ratio and measures of male and female genitals and secondary sexual characters across a large number of closely related taxa as an indirect way to 
compare different levels of sexual selection (House \& Lewis, 2007). Increasing levels of sexual selection increase the proportion of nutrients allocated in the making of sexual organs. Being the largest group of insects that complete the entire life-cycle as parasites, the parasitic lice (Insecta: Phthiraptera) offer an opportunity to outline and measure sexual characters in contagious pathogens. Like all insects, lice possess an articulated body structure consisting of distinctive body parts specialized for different functions; thus the size measures of body parts are more exact than in non-arthropod parasites or pathogens.

Since female lice may copulate several times throughout their life and they can also store sperm in their spermatheca, the male sex is likely to be subjected to sperm competition (Tryjanowski et al., 2009). Larger-bodied males, or those with relatively larger and more complex genitals, can produce more sperm to dilute the sperm of rivals and thus are more competitive. In Ischnoceran lice, the male antennae are often enlarged and serve to grasp females during copulation. Therefore, males with larger and more complex antennae can copulate for longer periods of time to prohibit other males from copulating subsequently. Finally, in species characterized by a higher level of sperm competition, female genitals are also predicted to be relatively larger and structurally more complex (House \& Lewis, 2007).

Obviously, the intensity of sperm competition is influenced by the proportion of males within the population. Skewed sex-ratios are common in lice, apparently originating from local mate competition (Clayton et al., 1992). This arises when a population is frequently and temporarily divided into several small subpopulations where inbreeding is pronounced (Hamilton, 1967). Lice tend to complete severallife-cycles on a single host individual while being isolated from conspecifics living on other hosts. Thus, females can maximize their breeding success by reducing the proportion of the more competitive sex (usually the male) to decrease sexual competition among the offspring. On the other hand, outbreeding favours the production of sexually competitive offspring.

Below, we quantify sexually selected morphological characters and sex-ratios in a diverse group of lice so as to investigate the relationships among sexual selection, geographic distribution, speciation and virulence. For this purpose we describe the co-variation of sex-ratio with sexually competitive morphological features, and the co-variation of environmental factors (such as geographical position and intensity of infection) and levels of sexual competition. Finally, we interpret these patterns in relation to parasite speciation and the evolution of virulence. 
Epidemiological measures, such as prevalence (Read et al., 1995a), mean intensity (Read et al., 1995b; Poulin, 1997a; Rózsa, 1997), and even host sociality (Rózsa et al., 1996) may covary with pathogen sex-ratios. Moreover, sex-ratio is correlated with sexual size dimorphism in parasitic nematodes (Poulin, 1997b) and sexual size dimorphism is also useful as a proxy of sexual selection in parasites (Poulin \& Morand, 2000; Tryjanowski et al., 2009). These findings were all interpreted within the context of sexual selection in parasites. Our present analysis, however, involves a much larger set of sexual characters and also takes geographical positions into account.

\subsubsection{Methodology}

Lice (Phthiraptera: Ischnocera: Geomydoecus spp., Thomomydoecus spp.) of pocket gophers (Mammalia: Rodentia: Geomyidae) were described by three co-working authors using large sample sizes (54 250 lice from 3574 gophers) and consistent morphometric methodologies (Price, 1975; Hellenthal \& Price, 1980; 1984; 1988; 1989a; 1989b; Price \& Hellenthal, 1975a; 1975b; 1976; 1979; 1980a; 1980b; 1980c; 1981a; 1981b; 1988a; 1988b; 1989a; 1989b; Price et al., 1985; Timm \& Price, 1979; 1980). We excluded a few erroneous or incomplete records, some small tropical samples collected south of Mexico, and samples of small size $(<25$ parasites or $<5$ hosts). Similarly, we removed apparently parthenogenetic (sex-ratios $<5 \%$ ) strains as outliers. In total, we included in the analyses 92 louse species and subspecies occurring on species and subspecies of pocket gophers broadly distributed over North and Central America. Because gopher diversity had been falsely inflated by giving subspecific ranks to local populations that differ only in size and coloration, but not divergent from others genetically, we united conspecific gopher 'subspecies' whenever they were not isolated geographically, following Hall (1981); Patton and Smith (1990); Hafner (1991); and Demastes et al. (2002). Host taxonomy follows Wilson and Reeder (1993).

Several louse species and subspecies are divided into two or more strains occurring on different gopher species or subspecies, and many gopher subspecies harbour two or more different strains belonging to different louse taxa. Overall, a total of 189 different strains can be identified. This complicated host-parasite system is also known to exhibit significant degrees of cospeciation (Hafner \& Nadler, 1988; Hafner et al., 1994). 
The following measures were obtained from the species descriptions to characterize parasite taxa:

1. Sex-ratio is the number of adult males divided by the total number of adults. After excluding apparent parthenogenetic strains, strain sex-ratio ranged from 0.34 to 0.79 .

2. Log-transformed male total body length is expressed as a linear function of log-transformed female total body length, then sexual size dimorphism (SSD) is expressed as residuals from this function (Ranta et al., 1994).

3. Female genital size is expressed as the length of female genital sac relative to total body length and is calculated similarly to SSD.

4. Male genital size is expressed as the width of male genital parameral arch relative to head width and is calculated similarly to SSD.

5. Male grasping organ size. The first segment of the male antenna is an enlarged grasping structure called the scape. Since males use it to fix the female thorax during copulation, we quantify male scape length in relation to conspecific female prothorax width. Scape length is calculated similarly to SSD.

6. The structural complexity of female genitals is the number of genital sac 'loops'. The function of these structures is not understood; we simply regard the genitals containing more loops to be structurally more complex than those with fewer loops. Character states are ordered as in Page et al. (1995).

7. Structural complexity of male genitals is quantified as the number of genital sac spines. The function of these structures is also unknown. Character states are ordered as in Page et al. (1995).

8. The structural complexity of the male grasping organ. The scape may come with or without a large protuberance. We interpret the presence of this structure as a manifestation of greater structural complexity. Character states are ordered as in Page et al. (1995). 
9. Finally, mean intensity is the number of parasites divided by the number of infected hosts, log-transformed. The random noise in these data is inherently high because most lice were collected from museum skins for taxonomic purposes only (Roger D. Price, personal communication). Given the very large sample size, they may still carry some information about true intensity values.

A few of the early species descriptions do not contain all of the above characters, thus not all data types were available for all taxa and thus sample sizes may differ among comparisons. Following Felsenstein (1985), we control for the potential effects of louse phylogeny. A cladistic tree produced by Page et al. (1995) provides an estimation of louse phylogeny; however, there is logical circularity in using it because some of the characters we analyse in this study were used directly in the construction of the tree itself. This error may not be large, however, as the sexually selected characters had a rather low character weight (as compared to all other characters) and had a weak influence on tree topology; sexually relevant morphological characters are nonconservative but show several independent cases of parallel evolution in gopher lice.

Nevertheless, to control for this potential error, we reconstructed the tree in Mesquite (Maddison \& Maddison, 2011) by excluding the characters analysed here from the original Page et al. (1995) data set. Given the large number of taxa, we performed a heuristic search for the most parsimonious tree using treelength as a criterion and SPR (Subtree Pruning and Regrafting) as the rearranger method. The consensus tree of the ten equally parsimonious trees was used in subsequent analyses along with the original Page et al. (1995) tree. We used phylogenetic generalized linear models as described by Freckleton et al. (2002) to control for phylogenetic non-independence. This method incorporates a phylogenetic variance-covariance matrix within a linear model. The assumptions of phylogenetic linear models were evaluated by diagnostic plots. Analyses were carried out by the 'caper' package (Orme et al., 2011) in R 2.14.0 (R Development Core Team, 2011). 


\subsubsection{Results and discussion}

When interpreting species characters as statistically independent events, thus applying no control for phylogeny, sex-ratio correlates positively with mean intensity, SSD and all the measures of the size and the structural complexity of female and male genitals, and male attachment organs (Table 4.1).

When applying phylogenetic control along the two trees mentioned above, sex-ratio correlates significantly with intensity $(\mathrm{N}=92$; slope $=0.08, \mathrm{r} 2=0.06, \mathrm{p}=0.012$ for our tree and slope $=$ 0.06, $\mathrm{r} 2=0.05, \mathrm{p}=0.023$ for Page et al.'s (1995) tree) and with male genital complexity ( $\mathrm{N}=92$; slope $=0.02, \mathrm{r} 2=0.05, \mathrm{p}=0.014$ and slope $=0.01, \mathrm{r} 2=0.05, \mathrm{p}=0.020$, respectively) . Furthermore, sex-ratio correlates significantly with relative male scape length in our tree, but this relationship is lost in the Page et al. (1995) tree $(\mathrm{N}=84$; slope $=0.49, \mathrm{r} 2=0.07, \mathrm{p}=0.007$ and slope $=0.19, \mathrm{r} 2=0.01, \mathrm{p}=0.19$, respectively).

In a multiple regression model, the significant explanatory variables (sex-ratio as response) were intensity (slope $=0.09, p=0.007$ ) and relative male scape length (slope $=0.52, r 2=0.14$, $p=0.003$ ) in our tree; and intensity (slope $=0.05, p=0.046$ ) and male genital complexity (slope $=0.01, r 2=0.08, p=0.040)$ in Page et al.'s (1995) tree.

Table 4.1 Co-variation of sex-ratio with mean intensity and sexually selected morphological characters across gopher louse species or subspecies (Spearman's correlations). All correlations lead into the direction predicted by the hypothesis that sperm competition is an influential agent of evolution in gopher lice.

Co-variation with

Mean intensity

SSD

Female genital size

Female genital structural complexity

Male genital size

Male genital structural complexity

Male grasping organ size

Male grasping organ structural complexity
N

92

92

78

92

91

92

84

92 $r$

0.2787

0.2575

0.3842

0.3658

0.3687

0.4021

0.2702

0.3492 p

0.0071

0.0132

0.0005

0.0003

0.0003

$<0.0001$

0.0129

0.0006 
We believe that outbreeding is likely to be more pronounced at higher intensities, and thus mean intensity predictably co-varies positively with male-to-male sexual competition. The direction of all correlations matches those predicted by the hypothesis that sexual selection is responsible for the emergence of these patterns.

Alternatively, these correlations can also be interpreted as a result of sampling bias. Because the larger-bodied parasites are easier to find than smaller ones, we expect sampling bias to yield an apparent correlation between SSD and sex-ratio. Furthermore, since SSD is correlated to all other morphological characters investigated here (details not shown) sampling bias could also explain correlations between apparent sex-ratio and all the morphological characters as mediated by SSD. However, the clear biogeographic pattern of sexually selected variability in gopher lice - as shown below - makes this latter hypothesis unlikely. In the absence of exact geographic coordinates, we use the political boundaries of the member states of Canada, the USA and Mexico to identify geographic locations.

The distribution of gopher lice sex-ratios exhibits a clear geographic pattern. Female-biased populations, and particularly the parthenogenetic ones, tend to occur on the periphery of the distribution. Conversely, male-biased populations are mostly found in the apparent speciation centre of gophers and gopher lice; i.e. roughly along the western side of the Great Basin Divide and along the Continental Divide in the south (Figure 4.3). 


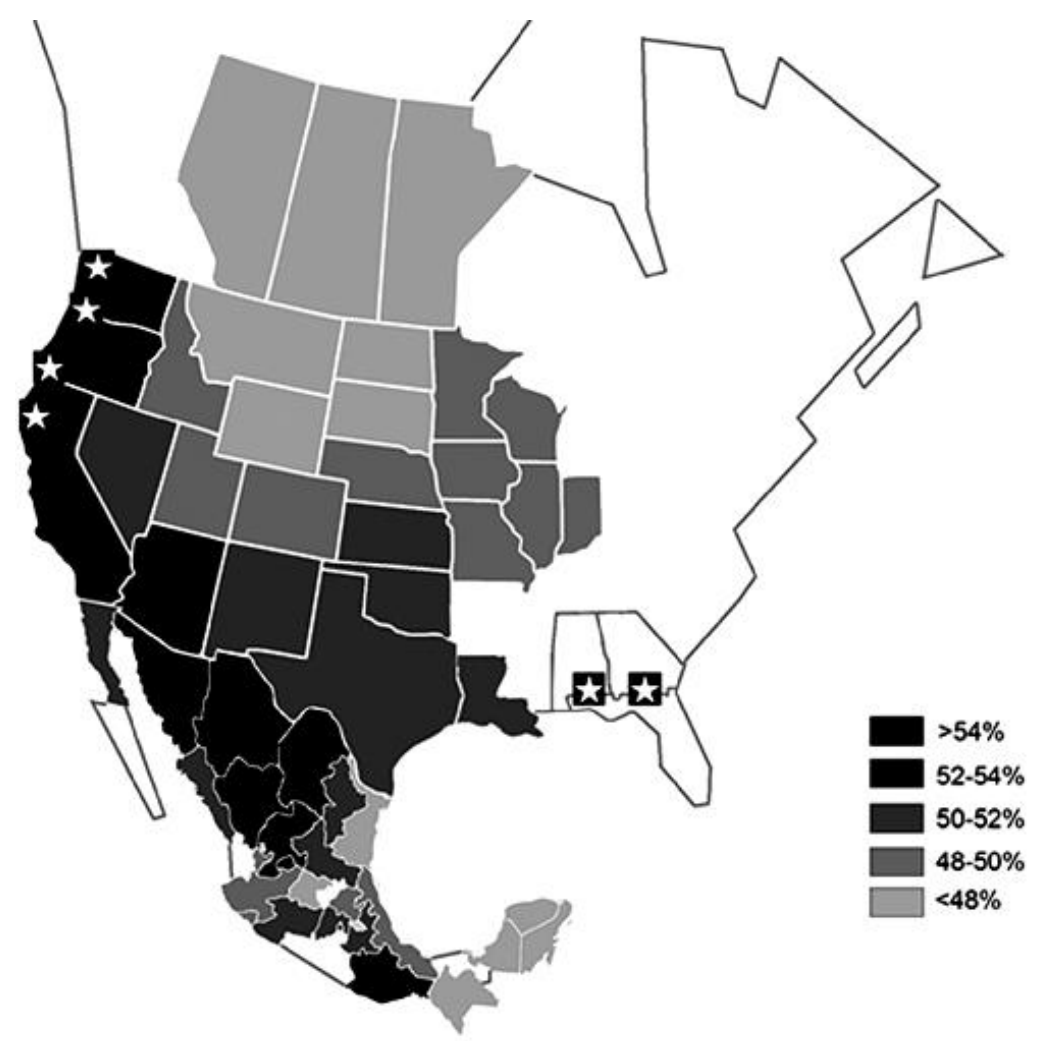

Figure 4.3 Geographic pattern of gopher louse sex-ratios. Each state is characterized by the mean of sex-ratios of the louse strains occurring there (provided that sample size $>=25$ parasites and $>=5$ hosts for each strain).

Parthenogenetic strains (stars) are excluded from calculations.

Moreover, after characterizing each member state of Canada, the USA and Mexico by the number of parasite strains per unit area, a significant positive correlation emerges between the density of louse strains per unit area and the mean of the sex-ratios of the strains. High sexratios tend to occur together with high strain density per unit area (Figure 4.4). 


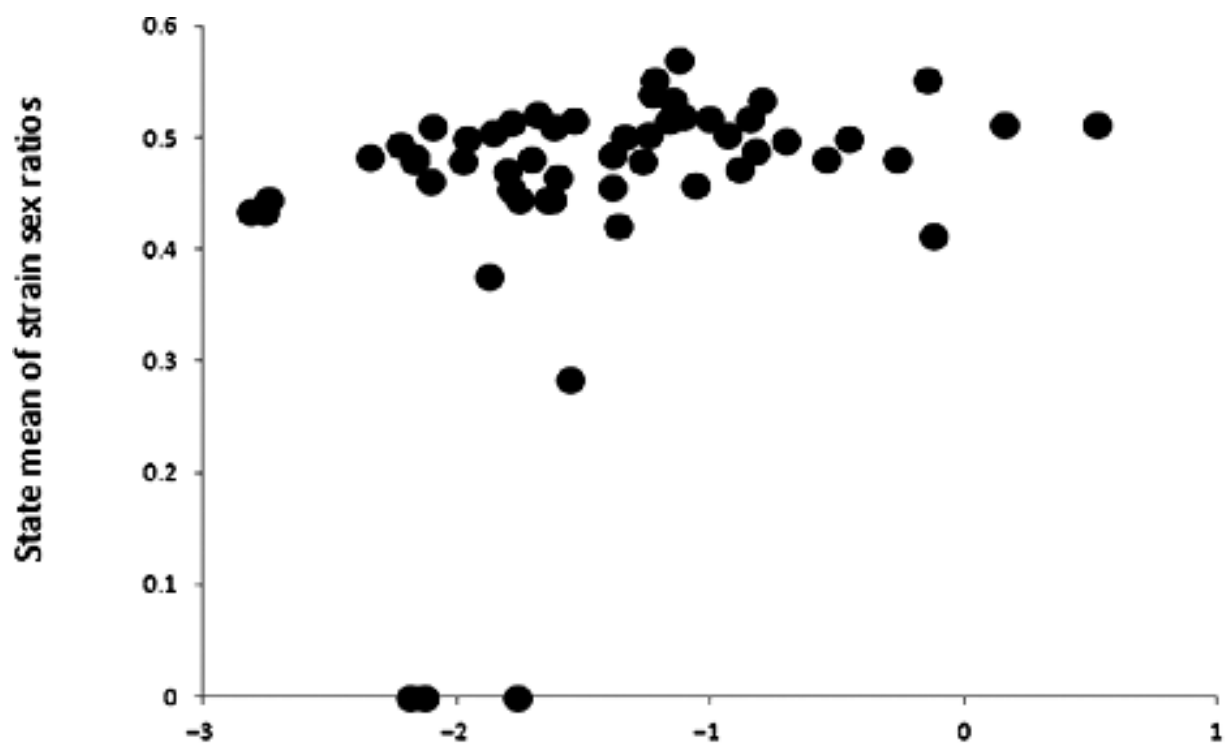

Figure 4.4 Parasite sex-ratios co-vary with strain density. Each circle represents a member state of Canada, the USA or Mexico. States are characterized by the number of parasite strains (different host-parasite species or subspecies pairs) per unit area, and the mean of parasite sex-ratios of strains occurring there. Spearman $r=0.4466$ (corrected for ties), $p=0.0006$.

Two alternative hypotheses may explain this co-variation. First, comparative evidence suggests that sexual selection often plays an important role in speciation of free-living animals (Panhuis et al., 2001). It is reasonable to assume that speciation and, thus, species richness may also be inflated by intense sexual selection in parasites and pathogens. Second, an opposite causality may also explain the patterns described above; high speciation rates may increase sexual selection. Speciation involves populations gradually diverging from each other, thus - before genetic isolation is completed - multiple infections originating from genetically different populations increase outbreeding and favour the production of sexually competitive offspring. This effect is less pronounced between genetically similar populations. Obviously, these two hypotheses are not mutually exclusive. In areas that permit high speciation rates for hosts and thus also for parasites, the two effects may interact as an autocatalytic process.

Another alternative is to presume that the interaction between geographic range and louse sexual characters is mediated by host characters (for example, body mass or longevity) unexplored by us. This hypothesis implies that the sex-ratio difference between strains of parasite A on host taxon 1 versus 2 should predict the sex-ratio difference between strains of 
parasite B on host taxon 1 versus host 2. Moreover, on a finer scale, the sex-ratio difference between local strains of parasite A on host local populations 1 versus 2 should predict the sexratio difference between louse strains of parasite $B$ on host populations 1 versus 2 . Pairwise comparisons across our data set do not support this prediction (details not shown), suggesting that the patterns presented above are not directly host-mediated.

In short, we are arguing that sexual competition may effectively shape the genitals and secondary sexual characters, sex-ratios and perhaps even speciation in gopher lice and that this process takes place within a strict biogeographic context. Intensive sexual selection is characteristic in the speciation centre, while sexually non-competitive forms (including parthenogenetic strains) occur on the periphery of the distribution.

Assuming that the same situation holds for other parasites and pathogens, the consequences are potentially far-reaching. Virulence is defined as the parasites' ability to reduce the survival and reproduction of infected hosts, and parasite population growth rate is a major component of it (Ewald, 1994). Our results suggest that a decrease in sexual competition on the periphery of the distribution results in female-biased sex-ratios and thus higher levels of population birth rates. However, their offspring predictably show lower survival rates due to their reduced genetic variability caused by inbreeding or parthenogenesis. Indeed, there is a strong, positive correlation between sex-ratio and intensity, indicating that higher birth rates come with lower parasite burdens in peripheral populations. The strength of sexual selection is known to co-vary with life history strategies interpreted along a classical $r-K$ continuum in free-living species (McLain, 1991). Similarly, parasites seem to trade birth rates against survival rates on the peripheries and vice versa in the range centre. Apparently, high parasite birth rates (indicated by the large proportion of females) represent only one component of virulence, while high parasite survival rates (due to a greater offspring genetic diversity) represent another component. Thus, we argue that different virulence components are traded against each other in different biogeographical positions, at least in the lice of pocket gophers, and perhaps in other pathogens as well. 


\subsection{Concluding remarks}

There is now ample evidence that climate change is reshuffling the geographic distributions of animal species worldwide (Parmesan \& Yohe, 2003). Several authors have emphasized that these distributional changes create new contact zones between parasites and formerly isolated hosts, enabling host-switches to new hosts, including humans. Not surprisingly, the case of emerging new parasites, pathogens and diseases is a major issue in current epidemiological thinking.

In our arguments above, we add further details potentially useful in the interpretation of current epidemiological processes and even in the prediction of future ones (Reperant, 2010). First, we do not lump all host-switch and host-shift events together. Rather, we typify host-switches as more characteristic at the leading edge of expanding host ranges, potentially resulting in parasite speciation. In contrast, host-shifts occur more often at the rear edge of the expanding host range and usually do not result in speciation. This latter process has not been characterized formerly, although its epidemiological role may well be important. Taking Central Africa as an example, where humans and non-human primates co-occur through long evolutionary periods, our hypothesis predicts that the recent gradual shrinking of ape populations may exert a selective pressure on their pathogens to abandon them and shift towards humankind.

Second, we differentiate between two alternative modes of host populations' forward advancement at the leading edge of an expanding range and thus resolve an apparent paradox about high pathogen burdens versus low pathogen burdens enhancing invasions. We argue that invasions initiated by few long-distance dispersive pioneers and followed by exponential growth of isolated host populations are enhanced by a competitive advantage due to invaders' speciespoor and genetically homogenous pathogen assemblage. In contrast, sudden mass invasions occurring both in human history and also in nature due to anthropogenic effects - may result in McNeill's effect. In this case, the invaders carry diverse pathogen burdens that they coevolved with through long periods and distribute these parasites to naive populations or species, causing high mortality and morbidity. 
Finally, by using a complex system of rodents and their parasitic lice as an example, we showed that parasite speciation may be facilitated by sexual selection - a factor neglected by most former authors. Accordingly, the leading edges of the moving host distribution may not equally facilitate parasite host-switches and speciation in different areas. Taking the poleward shift of host distribution edges as an example, it is rather safe to assume that the advancing northern margins in the north temperate and cold zones rarely coincide with the speciation centres of major pathogen taxa. Thus we cannot agree with former arguments claiming that emerging parasitic diseases are expected to originate particularly from temperate and colder northern latitudes (Mas-Coma et al., 2008). Conversely, the leading edges may often come into direct contact with pathogen speciation centres in tropical and subtropical zones, and these are the areas from which we expect the new pathogens and parasites to emerge - partly due to hostswitches and host-shifts occurring here.

Some of the arguments described above are admittedly hypotheses awaiting validation or falsification by future empirical tests. It is also not quite clear how far these arguments may be generalized. For example, certain host invasions are not of a geographical nature, but rather cross the line of demarcation between major habitat types. We already know that avian and mammalian clades' shifting from terrestrial to aquatic habitats decimates the richness of their original parasite faunae (Aznar et al., 2001; Felső \& Rózsa, 2006), creating long-lasting unsaturated parasite communities; however, we cannot know whether or not there are also other similarities to invasions in the geographical sense.

Acknowledgements

This research was supported by the European Union and the State of Hungary, co-financed by the European Social Fund in the framework of TÁMOP 4.2.4. A/2-11-1-2012-0001 'National Excellence' Program. Zoltán Vas was supported by the National Scientific Research Fund of Hungary (OTKA grant no. 108571). 
References

Anderson, M. (1994). Sexual Selection. Princeton, NJ: Princeton University Press.

Aznar, F. J., Balbuena, J. A., Fernández, M. \& Raga, J. A. (2001). Living together: the parasites of marine mammals. In Evans, P. \& Raga, J. (eds), Marine Mammals: Biology and Conservation, New York: Kluwer Academic/Plenum Publishers, pp. 385-423.

Bordes, F., Morand, S., Krasnov, B. R. \& Poulin, R. (2010). Parasite diversity and latitudinal gradients in terrestrial mammals. In Morand, S. \& Krasnov, B. (eds), The Biogeography of Host-Parasite Interactions, Oxford: Oxford University Press, pp. 89-98.

Clayton, D. H., Gregory, R. D. \& Price, R. D. (1992). Comparative ecology of Neotropical bird lice (Insecta: Phthiraptera). Journal of Animal Ecology, 61, 781-795.

Demastes, J. W., Spradling, T. A., Hafner, M. S., Hafner, D. J. \& Reed, D. L. (2002). Systematics and phylogeography of Pocket Gophers in the genera Cratogeomys and Pappogeomys. Molecular Phylogenetics and Evolution, 22, 144-154.

Diamond, J. (1997). Guns, Germs and Steel: The Fates of Human Societies. New York and London: Norton \& Company.

Dynesius, M. \& Jansson, R. (2000). Evolutionary consequences of changes in species' geographical distributions driven by Milankovitch climate oscillations. Proceedings of the National Academy of Sciences of the United States of America, 97, 9115-9120.

Ewald, P. W. (1994). Evolution of Infectious Disease. New York: Oxford University Press.

Felsenstein, J. (1985). Phylogenies and the comparative method. American Naturalist, 125, $1-$ 15.

Felső, B. \& Rózsa, L. (2006). Reduced taxonomic richness of lice (Insecta: Phthiraptera) in diving birds. Journal of Parasitology, 92, 867-869.

Freckleton, R. P., Harvey, P. H. \& Pagel, M. (2002). Phylogenetic analysis and comparative data: a test and review of evidence. American Naturalist, 160, 712-726.

Hafner, M. S. (1991). Evolutionary genetics and zoogeography of Middle American Pocket Gophers, genus Orthogeomys. Journal of Mammalogy, 72, 1-10. 
Hafner, M. S. \& Nadler, S. A. (1988). Phylogenetic trees support the coevolution of parasites and their hosts. Nature, 332, 258-259.

Hafner, M. S., Sudman, P. D., Villablanca, F. X., et al. (1994). Disparate rates of molecular evolution in cospeciating hosts and parasites. Science, 265, 1087-1090.

Hall, E. R. (1981). The Mammals of North America. 2nd edn. New York: Wiley Interscience.

Hamilton, W. D. (1967). Extraordinary sex ratios. Science, 156, 477-488.

Hamilton, W. D., Axelrod, R. \& Tanese, R. (1990). Sexual reproduction as an adaptation to resist parasites (a review). Proceedings of the National Academy of Sciences of the USA, 87, 3566.

Hampe, A. \& Petit, R. J. (2005). Conserving biodiversity under climate change: the rear edge matters. Ecology Letters, 8, 461-467.

Hellenthal, R. A. \& Price, R. D. (1980). A review of the Geomydoecus subcalifornicus complex (Mallophaga: Trichodectidae) from Thomomys pocket gophers (Rodentia: Geomyidae) with a discussion of quantitative techniques and automated taxonomic procedures. Annals of the Entomological Society of America, 73, 495-503.

Hellenthal, R. A. \& Price, R. D. (1984). A new species of Thomomydoecus (Mallophaga: Trichodectidae) from Thomomys bottae pocket gophers (Rodentia: Geomyidae). Journal of the Kansas Entomological Society, 57, 231-236.

Hellenthal, R. A. \& Price, R. D. (1988). Geomydoecus (Mallophaga: Trichodectidae) from the Texas and desert pocket gophers (Rodentia: Geomyidae). Proceedings of the Entomological Society of Washington, 91, 1-8.

Hellenthal, R. A. \& Price, R. D. (1989a). The Thomomydoecus wardi complex (Mallophaga: Trichodectidae) of the pocket gopher, Thomomys talpoides (Rodentia: Geomyidae). Journal of the Kansas Entomological Society, 62, 245-253.

Hellenthal, R. A. \& Price, R. D. (1989b). Geomydoecus thomomyus complex (Mallophaga: Trichodectidae) frompocket gophers of the Thomomys talpoides complex (Rodentia: Geomyidae) of the United States and Canada. Annals of the Entomological Society of America, 82, 286-297.

Hewitt, G. M. (2000). The genetic legacy of the ice ages. Nature, 405, 907-913. 
Hoberg, E. P. \& Brooks, D. R. (2008). A macroevolutionary mosaic: episodic host-switching, geographical colonization and diversification in complex host-parasite systems. Journal of Biogeography, 35, 1533-1550.

House, C. M. \& Lewis, Z. (2007). Genital evolution: blurring the battle lines between the sexes. Current Biology, 17, R1013-R1014.

Hudson, P. \& Greenman, J. (1998). Competition mediated by parasites: biological and theoretical progress. Trends in Ecology \& Evolution, 13, 387-390.

Karl, T. R. \& Trenberth, K. E. (2003). Modern global climate change. Science, 302, 1719.

Keane, R. M. \& Crawley, M. J. (2002). Exotic plant invasions and the enemy release hypothesis. Trends in Ecology \& Evolution, 17, 164-170.

Krasnov, B. R., Mouillot, D., Shenbrot, G. I., Khokhlova, I. S. \& Poulin, R. (2004). Geographical variation in host specificity of fleas (Siphonaptera) parasitic on small mammals: the influence of phylogeny and local environmental conditions. Ecography, 27, 787-797.

Lafferty, K. D. (2012). Biodiversity loss decreases parasite diversity: theory and patterns. Philosophical Transactions of the Royal Society B, 367, 2814-2827.

Maddison, W. P. \& Maddison, D. R. (2011). Mesquite: A Modular System for Evolutionary Analysis Version 2.75, www.mesquiteproject.org/mesquite/mesquite.html, accessed June 2013.

Mas-Coma, S., Valero, M. A. \& Bargues, M. D. (2008). Effects of climate change on animal and zoonotic helminthiases. Revue Scientifique et Technique/Office International des Epizooties, 27, 443-452.

McLain, D. K. (1991). The $\mathrm{r}-\mathrm{K}$ continuum and the relative effectiveness of sexual selection. Oikos, 60, 263-265.

McNeill, W. H. (1976). Plagues and People. New York: Anchor Press.

Murray, K. A., Skerratt, L. F., Speare, R., et al. (2012). Cooling off health security hot spots: getting on top of it down under. Environment International, 48, 56-64.

Orme, D., Freckleton, R. P., Thomas, G., et al. (2011). caper: Comparative Analyses of Phylogenetics and Evolution in R. R package version 0.4, www.CRAN.R-project.org/ package=caper, accessed June 2013. 
Page, R. D. M., Price, R. D. \& Hellenthal, R. A. (1995). Phylogeny of Geomydoecus and Thomomydoecus pocket gopher lice (Phthiraptera: Trichodectidae) inferred from cladistic analysis of adult and first instar morphology. Systematic Entomology, 20, 129143.

Panhuis, T. M., Butlin, R., Zuk, M. \& Tregenza, T. (2001). Sexual selection and speciation. Trends in Ecology \& Evolution, 16, 364-371.

Parmesan, C. \& Yohe, G. (2003). A globally coherent fingerprint of climate change impacts across natural systems. Nature, 421, 37-42.

Patton, J. L. \& Smith, M. F. (1990). The evolutionary dynamics of the pocket gopher Thomomys bottae. University of California Publications in Zoology, 123, 1-161.

Petit, R. J., Aguinagalde, I., de Beaulieu, J. L., et al. (2003). Glacial refugia: hotspots but not melting pots of genetic diversity. Science, 300, 1563-1565.

Poulin, R. (1997a). Population abundance and sex ratio in dioecious helminth parasites. Oecologia, 111, 375-380.

Poulin, R. (1997b). Covariation of sexual size dimorphism and adult sex ratio in parasitic nematodes. Biological Journal of the Linnean Society, 62, 567-580.

Poulin, R. (2008). Evolutionary Ecology of Parasites, Princeton, NJ and Oxford: Princeton University Press.

Poulin, R. \& Morand, S. (2000). Testes size, body size and male-male competition in acanthocephalan parasites. Journal of Zoology, 250, 551-558.

Price, R. D. (1975). The Gemydoecus (Mallophaga: Trichodectidae) of the Southeastern USA pocket gophers (Rodentia: Geomyidae). Proceedings of the Entomological Society of Washington, 77, 61-65.

Price, R. D. \& Hellenthal, R. A. (1975a). A reconsideration of Geomydoecus expansus (Duges) (Mallophaga: Trichodectidae) from the yellow-faced pocket gopher (Rodentia: Geomyidae). Journal of the Kansas Entomological Society, 48, 33-42.

Price, R. D. \& Hellenthal, R. A. (1975b). A review of the Geomydoecus texanus complex (Mallophaga: Trichodectidae) from Geomys and Pappogeomys (Rodentia: Geomyidae). Journal of Medical Entomology, 12, 401-408. 
Price, R. D. \& Hellenthal, R. A. (1976). The Geomydoecus (Mallophaga: Trichodectidae) from the hispid pocket gopher (Rodentia: Geomyidae). Journal of Medical Entomology, 12, 695-700.

Price, R. D. \& Hellenthal, R. A. (1979). A review of the Geomydoecus tolucae complex (Mallophaga: Trichodectidae) from Thomomys (Rodentia: Geomyidae), based on qualitative and quantitative characters. Journal of Medical Entomology, 16, 265-274.

Price, R. D. \& Hellenthal, R. A. (1980a). The Geomydoecus oregonus complex (Mallophaga: Trichodectidae) of the Western United States pocket gophers (Rodentia: Geomyidae). Proceedings of the Entomological Society of Washington, 82, 25-38.

Price, R. D. \& Hellenthal, R. A. (1980b). The Geomydoecus neocopei complex (Mallophaga: Trichodectidae) of the Thomomys umbrinus pocket gophers (Rodentia: Geomyidae) of Mexico. Journal of the Kansas Entomological Society, 53, 567-580.

Price, R. D. \& Hellenthal, R. A. (1980c). A review of the Geomydoecus minor complex (Mallophaga: Trichodectidae) from Thomomys (Rodentia: Geomyidae). Journal of Medical Entomology, 17, 298-313.

Price, R. D. \& Hellenthal, R. A. (1981a). A review of the Geomydoecus californicus complex (Mallophaga: Trichodectidae) from Thomomys (Rodentia: Geomyidae). Journal of Medical Entomology, 18, 1-23.

Price, R. D. \& Hellenthal, R. A. (1981b). Taxonomy of the Geomydoecus umbrini complex (Mallophaga: Trichodectidae) from Thomomys umbrinus (Rodentia: Geomyidae) in Mexico. Annals of the Entomological Society of America, 74, 37-47.

Price, R. D. \& Hellenthal, R. A. (1988a). A new species of Geomydoecus (Mallophaga: Trichodectidae) from Pappogeomys (Rodentia: Geomyidae) pocket gophers in Jalisco, Mexico. Journal of Entomological Science, 23, 212-215.

Price, R. D. \& Hellenthal, R. A. (1988b). Geomydoecus (Mallophaga: Trichodectidae) from the Central American pocket gophers of the subgenus Orthogeomys (Rodentia: Geomyidae). Journal of Medical Entomology, 25, 331-335.

Price, R. D. \& Hellenthal, R. A. (1989a). Geomydoecus (Mallophaga: Trichodectidae) from Pappogeomys and Zygogeomys pocket gophers (Rodentia: Geomyidae) in Central Mexico. Journal of Medical Entomology, 26, 385-401. 
Price, R. D. \& Hellenthal, R. A. (1989b). Geomydoecus bulleri complex (Mallophaga: Trichodectidae) from Buller's pocket gopher Pappogeomys bulleri (Rodentia: Geomyidae), in Westcentral Mexico. Annals of the Entomological Society of America, 82, 279-285.

Price, R. D., Hellenthal, R. A. \& Hafner, M. S. (1985). The Geomydoecus (Mallophaga: Trichodectidae) from the Central American pocket gophers of the subgenus Macrogeomys (Rodentia: Geomyidae). Proceedings of the Entomological Society of Washington, 87, 432-443.

R Development Core Team (2011). R: A Language and Environment for Statistical Computing. Vienna: R Foundation for Statistical Computing, www.R-project.org.

Ranta, E., Laurila, A. \& Elmberg, J. (1994). Reinventing the wheel: analysis of sexual dimorphism in body size. Oikos, 70, 313-321.

Read, A. F., Anwar, M., Shutler, D. \& Nee, S. (1995a). Sex allocation and population structure in malaria and related parasitic protozoa. Proceedings of the Royal Society of London B, 260, 359-363.

Read, A. F., Narara, A., Nee, S., Keymer, A. E. \& Day, K. P. (1995b). Gametocyte sex ratios as indirect measures of outcrossing rates in malaria. Parasitology, 104, 387-395.

Reperant, L. A. (2010). Applying the theory of island biogeography to emerging pathogens: toward predicting the sources of future emerging zoonotic and vector-borne diseases. Vector- Borne and Zoonotic Diseases, 10, 105-110.

Ricklefs, R. E. (2010). Host-pathogen coevolution, secondary sympatry and species diversification. Philosophical Transactions of the Royal Society B, 365, 1139-1147.

Rosenzweig, C., Karoly, D., Vicarelli, M., et al. (2008). Attributing physical and biological impacts to anthropogenic climate change. Nature, 453, 353-357.

Rózsa, L. (1997). Adaptive sex-ratio manipulation in Pediculus humanus capitis: possible interpretation of Buxton's data. Journal of Parasitology, 83, 543-544.

Rózsa, L. (2005). Parasitism: The Driving Force of Animal and Human Evolution. Budapest: Medicina. (In Hungarian) 
Rózsa, L., Rékási, J. \& Reiczigel, J. (1996). Relationship of host coloniality to the population ecology of avian lice (Insecta: Phthiraptera). Journal of Animal Ecology, 65, 242-248.

Thomas, C. D., Cameron, A., Green, R. E., et al. (2004). Extinction risk from climate change. Nature, 427, 145-148.

Timm, R. M. \& Price, R. D. (1979). A new species of Geomydoecus (Mallophaga:

Trichodectidae) from the Texas pocket gopher, Geomys personatus (Rodentia: Geomyidae). Journal of the Kansas Entomological Society, 52, 264-268.

Timm, R. M. \& Price, R. D. (1980). The taxonomy of Geomydoecus (Mallophaga: Trichodectidae) from the Geomys bursarius complex (Rodentia: Geomyidae). Journal of Medical Entomology, 17, 126-145.

Tompkins, D. M., Draycott, R. A. H. \& Hudson, P. J. (2002). Field evidence for apparent competition mediated via the shared parasites of two gamebird species. Ecology Letters, $3,10-14$.

Torchin, M. E., Lafferty, K. D., Dobson, A. P., McKenzie, V. J. \& Kuris, A. M. (2003). Introduced species and their missing parasites. Nature, 421, 628-630.

Tryjanowski, P., Adamski, Z., Dylewska, M., Bulkai, L. \& Rózsa, L. (2009). Demographic correlates of sexual size dimorphism and male genital size in the lice Philopterus coarctatus. Journal of Parasitology, 95, 1120-1124.

Wilson, D. E. and Reeder, D. M. (eds) (1993). Mammalian Species of the World: A Taxonomic and Geographic Reference, 2nd edn. Washington, DC: Smithsonian Institution Press. 